\title{
The Surgical Outcome of Traumatic Extraaxial Hematomas Causing Brain Herniation
}

\author{
Bora GURER ${ }^{1}$, Hayri KERTMEN², Erdal Resit YILMAZ², Habibullah DOLGUN², Askin Esen HASTURK \\ Zeki SEKERCI ${ }^{2}$
}

${ }^{1}$ Fatih Sultan Mehmet Education and Research Hospital, Neurosurgery Clinic, Istanbul, Turkey

${ }^{2}$ Diskapi Yildirim Beyazit Education and Research Hospital, Neurosurgery Clinic, Ankara, Turkey

${ }^{3}$ Oncology Education and Research Hospital, Neurosurgery Clinic, Ankara, Turkey

\section{ABSTRACT}

AIM: The aim of this study was to assess the surgical outcome and the prognostic importance of clinical and radiological data of patients operated emergently for an extraaxial hematoma causing brain herniation.

MATERIAL and METHODS: This retrospective study comprised 108 adult patients who were operated due to herniated traumatic extraaxial hematomas from January 2000 to January 2013.

RESULTS: Of 108 patients, 63 patients (58.3\%) were diagnosed as subdural hematoma (SDH), and 45 patients (41.7\%) as epidural hematoma $(\mathrm{EDH})$. An unfavorable outcome was significantly increased for patients who were diagnosed as SDH (90.4\%) compared with EDH patients (33.3\%). Mortality rate for herniated SDH patients was $65.1 \%$, and $26.6 \%$ for herniated EDH patients. High mortality and unfavorable outcome ratios were associated with Glasgow Coma Scale scores at admission, mean postoperative intracranial pressure (ICP) values, type of the brain herniation, interval from the time of trauma to the time of hematoma decompression, the duration of the brain herniation, intraoperative acute brain swelling, hematoma volume and thickness, degree of the midline shift and the obliteration of the basal cisterns.

CONCLUSION: Our data showed that, postoperative ICP values were one most important predictor of the mortality. We recommended postoperative ICP monitoring for all patients presenting with the brain herniation due to traumatic extraaxial hematoma.

KEYWORDS: Epidural hematoma, Herniation, Intracranial pressure, Outcome, Subdural hematoma

\section{INTRODUCTION}

A ccident is the leading cause of death among individuals younger than 45 years. Traumatic brain injury (TBI) accounts for approximately $70 \%$ of these traumatic deaths and most of the unfavorable outcomes (2). The most important complication of TBI is the development of intracranial hematomas. It is estimated that intracranial hematomas occur in $25-45 \%$ of severe $\mathrm{TBI}, 3-12 \%$ of moderate cases and approximately 1 in 500 patients with mild TBI (40). As a result, acute traumatic extraaxial hematomas (epidural hematoma $(\mathrm{EDH})$ and subdural hematoma $(\mathrm{SDH})$ ), are among the most common clinical entities encountered by any neurosurgical service.

Brain herniation due to posttraumatic hematoma remains one of the most difficult situation faced by neurosurgeons, and causes significant mortality and morbidity. To our knowledge there were only few past studies focused especially into the herniated subgroup of traumatic extraaxial hematomas $(31,37,43,44)$.

The aim of this retrospective study was to assess the surgical outcome and the prognostic importance of clinical and 
Gurer B. et al: Traumatic Herniated Extraaxial Hematomas

radiological data of patients operated emergently upon for an extraaxial hematoma causing brain herniation.

\section{MATERIAL and METHODS}

This retrospective study comprised 108 adult patients who were operated due to herniated traumatic extraaxial hematomas from January 2000 to January 2013 in two neurosurgical clinics (Diskapi Education and Research Hospital and Oncology Training and Research Hospital). Clinical and imaging information was obtained through a retrospective review of the medical records and the radiographs. The criteria for inclusion were the patients accepted to the hospital with head injury and who underwent surgery due to extraaxial hematomas, causing brain herniation. Extraaxial hematomas were diagnosed by non-contrast computed tomography (CT) and the patients were classified due to having $\mathrm{EDH}$ or SDH. Anisocoria and lack of pupil reaction with midline shift in the admission CT were determined as the indicators of a brain herniation.

Demographic data, mechanism of the trauma, Glasgow Coma Scale (GCS) score at the time of admission, pupillary reactivity, and the duration of the intensive care unit (ICU) stay were reviewed from medical records. A ventricular or parenchymal fiberoptic intracranial pressure (ICP) monitoring catheter (Camino, Integra Life Science Corporation, Plainsboro, NJ, USA or Codman, Codman and Shurtleff Incorporation, Raynham, MA, USA) was inserted during the surgery in all patients to assist postoperative management. Patients whose postoperative ICP data were missing or to whom no ICP monitor was inserted were excluded from the study. The ICP data were recorded in the patients' documentation, on an hourly basis, by the ICU nurses. In the case of a high ICP peak, this was recorded as well and included in the data analysis for that hour. We evaluated the mean values of the entire ICP monitoring period postoperatively depending on hourly measurements.

Brain herniation syndromes, as evidenced by radiologic and neurologic examinations, were classified into three categories as follows: ipsilateral uncal herniation, bilateral uncal herniation and Kernohan's herniation. Uncal herniation was defined as cases of mydriasis ipsilateral to the clot along with contralateral hemiplegia. Kernohan's herniation represented a state with both mydriasis and hemiplegia ipsilateral to the clot (17).

The intervals from the time of trauma to the time of hematoma decompression as well as the entire operation time needed and the length of the period of brain herniation were recorded. The decompression time was defined as 30 minutes after the scalp incision, which represents an estimated time of hematoma evacuation. The length of the period of brain herniation, defined as the time period between the onset of anisocoria and the decompression time.

All patients were operated on by four senior surgeons with evacuation of the hematoma via craniotomy (CO) or craniectomy (CE) with duraplasty due to surgeon's intraoperative judgment. Operative records were also reviewed to determine if intraoperative brain swelling was recognized.

The location of the lesions were verified and recorded from both CT and operative findings. Hematoma volume was measured by the empirical formula of volume $(0.5 \mathrm{x}$ height $\mathrm{x}$ depth $x$ length) on the basis of distance measurements of the depth and length on the CT slice having the largest area of clot (28). The hematoma thickness was measured as the largest vertical distance between the cortex and the tabula interna (Figure 1A) and the midline shift as the largest perpendicular distance between an imaginary reference joining the frontal crest and the protuberantia occipitalis interna and the most shifted point of the septum pellucidum (Figure 1B). The other variables analyzed by CT scanning included associated lesions and the obliteration of the basal cisterns (Figure 2A). Associated lesions were defined as subarachnoid hemorrhage $(\mathrm{SAH})$ or brain contusion (Figure $2 \mathrm{~B}$ ).

Functional outcome was evaluated 6 months after injury by Glasgow Outcome Scale (GOS) score as follows: 5= good recovery, 4= moderate disability, $3=$ severe disability,
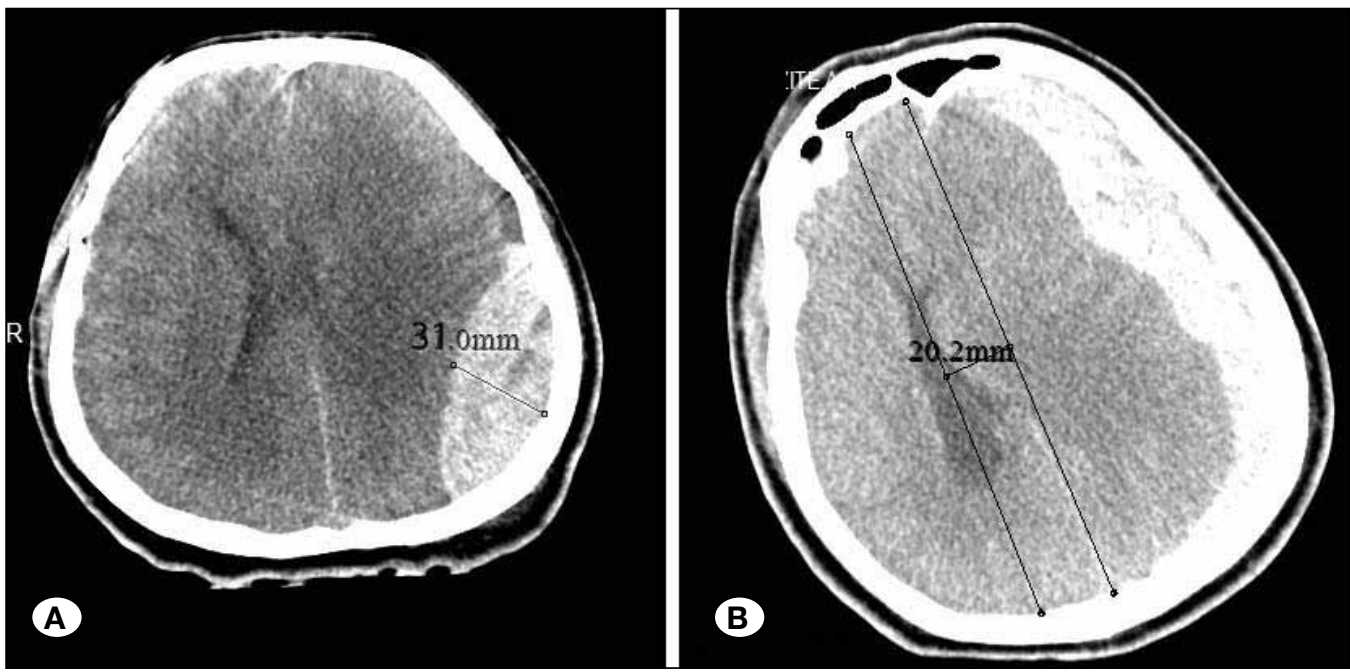

Figure 1: The thickness of the hematoma $(\mathbf{A})$ and the midline shift measurements (B) showed on the CT scans. 
$2=$ vegetative state, and $1=$ death (15). Good recovery or moderate disability is referred to in terms of "favorable outcome", whereas the remaining three categories are classified as "unfavorable outcome".

\section{Statistical Analysis}

Data analysis was performed by using SPSS for Windows, version 11.5 (SPSS Inc., Chicago, IL, United States). Whether the distributions of continuous variables were normally or not was determined by Shapiro-Wilk test. Data were shown as mean \pm SD or median (min-max), where applicable. The mean differences between groups were evaluated by Student's t test, while the Mann-Whitney $U$ test was applied for the comparisons of the median values. Nominal data were analyzed by Pearson's Chi-square or Fisher's exact test, where appropriate. Whether the potential risk factors were statistically significant affect on mortality going on or not was evaluated by Multiple Logistic Regression Analysis Backward LR method. Any variable whose univariable test had a $p$ value $<0.25$ was accepted as a candidate for the multivariable model along with all variables of known clinical importance. Odds ratios and $95 \%$ confidence intervals for each independent variable were also calculated. A p value less than 0.05 was considered statistically significant.

\section{RESULTS}

Of 108 patients, 63 patients (58.3\%) were diagnosed as SDH and 45 patients $(41.7 \%)$ as $\mathrm{EDH}$. Only 36 of the 108 patients (33.3\%) showed a favorable outcome. An unfavorable outcome was significantly increased for patients who were diagnosed as SDH $(90.4 \%)$ compared with EDH patients $(33.3 \%)(p<0.001)$. The mortality rate was $65.1 \%$ for herniated SDH patients and $26.6 \%$ for herniated EDH patients. This high mortality rate for $\mathrm{SDH}$ patients was statistically significant when compared to the mortality rate of herniated EDH patients $(p<0.001)$.

The age of the patients ranged from 18 to 78 years old, with a median of 36 years old. No statistically significant difference was determined between age groups both for mortality and functional outcome rates. There were 87 males $(80.5 \%)$ and 21 females (19.5\%). The mortality and functional outcome rates were not significantly different between sexes among all study cohorts $(p=0.302)$. On the other hand mortality was determined to be higher in females with $\operatorname{EDH}(p=0.043)$.

Motor vehicle accidents were the leading cause of trauma $(n=61,56.5 \%)$ followed by falls $(n=15,13.9 \%)$, pedestrian injuries $(n=13,12 \%)$, assaults $(n=10,9.2 \%)$, motorcycle accidents $(n=7,6.5 \%)$, and bicycle accidents $(n=2,1.9 \%)$. Trauma mechanism showed no significance in both mortality and functional outcome rates. The demographic values of the patients are summarized in Table I.

Mortality and unfavorable outcome were highly correlated with GCS scores at admission ( $p<0.001$ for both). The median GCS score was 4 (range 3-8) for the patients who died, and 6 (range 3-9) for the patients who were alive; patients who died showed statistically significantly lower median GCS scores. Patients in whom a favorable outcome was achieved had a median GCS of 7 (range 4-9), and patients who had unfavorable outcome showed a lower median GCS score (4, range 3-8).

Patients who had bilateral unreactive pupils before surgery had significantly higher mortality $(p=<0.001)$ and unfavorable outcome $(p=0.009)$. However, bilateral unreactive pupils did not show any statistical significance regarding mortality $(p=0.145)$ and unfavorable outcome $(p=1)$ when the subgroup of $\mathrm{SDH}$ patients was analyzed.

The duration of ICU did not affect mortality $(p=0.248)$ or favorable outcome (0.837). In the EDH subgroup, the longer ICU stays were associated with more mortality $(p=0.025)$ and more unfavorable outcome $(p=0.038)$. In contrast, the duration of ICU stay was longer in those who survived $(p=0.002)$ and those in whom a favorable outcome was achieved $p=0.015)$ in the SDH subgroup.

Mortality was highly correlated with mean postoperative ICP values $(p<0.001)$. Patients who died showed significantly

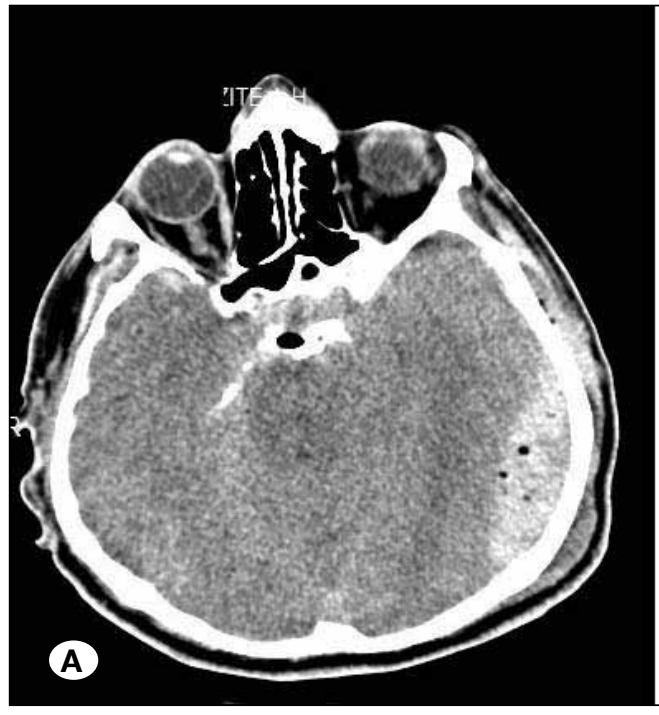

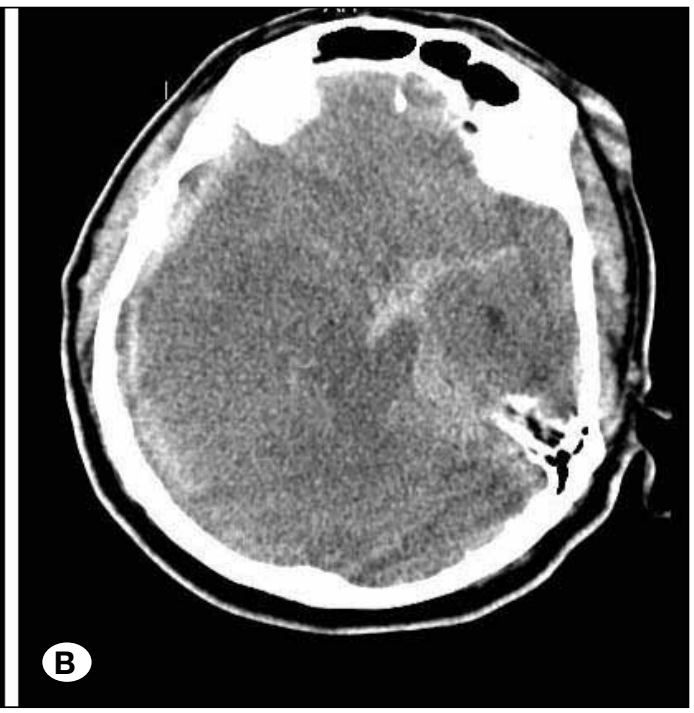

Figure 2: Obliteration of the basal cisterns (A) and coincident lesion as SAH (B) are shown on the CT scans. Both these entities were associated with high mortality and unfavorable outcome. 
Table I: Demographic Features of the Patients

\begin{tabular}{lcc}
\hline \multicolumn{1}{l}{ Sex } & Number & $\%$ \\
\hline \multicolumn{1}{l}{ Male } & & \\
\hline Female & 87 & 80.5 \\
\hline Diagnosis & 21 & 19.5 \\
\hline SDH & & \\
\hline EDH & 63 & 58.3 \\
\hline Mechanism of the injury & 45 & 41.7 \\
\hline Motor vehicle accidents & & \\
\hline Falls & 61 & 56.5 \\
\hline Pedestrian injuries & 15 & 13.9 \\
\hline Assaults & 13 & 12 \\
\hline Motorcycle accidents & 10 & 9.2 \\
\hline Bicycle accidents & 7 & 6.3 \\
\hline Location of the hematoma & 2 & 1.9 \\
\hline Frontoparietal and frontotemporal & 61 & 56.5 \\
\hline Temporal & 29 & 26.9 \\
\hline Parietooccipital & 9 & 8.3 \\
\hline Posterior Fossa & 9 & 8.3 \\
\hline
\end{tabular}

EDH: Epidural hematoma; SDH: Subdural hematoma.

higher ICP values (mean= $29 \mathrm{mmHg}$, range 21-36 $\mathrm{mm} \mathrm{Hg}$ ) compared with the patients who were alive (mean $=19 \mathrm{mmHg}$, range $12-33 \mathrm{~mm} \mathrm{Hg}$ ). The favorable outcome was also highly correlated with mean postoperative ICP values $(p<0.001)$. Patients with favorable outcome showed significantly lower ICP values (mean= $15.5 \mathrm{mmHg}$, range $12-28 \mathrm{mmHg}$ ) compared with patients with unfavorable outcome (mean $=29$ $\mathrm{mmHg}$, range 16-36 $\mathrm{mmHg}$ ).

Type of brain herniation significantly affected the mortality. Bilateral uncal herniation represented a strong predictor for mortality with $93.3 \%$ mortality rate when compared with ipsilateral uncal herniation (42.2\% mortality) and with Kernohan's herniation syndrome $(33.3 \%$ mortality) $(p<0.001)$. Also, the presence of bilateral uncal herniation is one of the predictors of an unfavorable outcome $(p=0.018)$. In the SDH subgroup, the type of the herniation did not affect the mortality $(p=0.14)$ and unfavorable outcome $(p=0.315)$.

The longer interval from the time of the trauma to the time of the hematoma decompression was significantly correlated with high mortality rate $(p<0.001)$ and high unfavorable outcome rate $(p<0.001)$.

The length of the operation time was correlated with both mortality and unfavorable outcome; where the longer the operation time, higher the incidence of mortality and unfavorable outcome $(p=<0.001$ for both). There was no statistically significant association between the length of the operation time and mortality $(p=0.485)$ or unfavorable outcome $(p=0.882)$ in the SDH subgroup.

The duration of the brain herniation strongly correlated with mortality and unfavorable outcome, i.e., the longer the period of brain herniation the higher the incidence of mortality $(p<0.001)$ and unfavorable outcome $(p<0.001)$.

In the CE group, mortality was higher (75\%) compared to the CO group $(5 \%)(p<0.001)$. A favorable outcome was achieved in only $4.4 \%$ of patients in the CE group and $82.5 \%$ of the patients in the $\mathrm{CO}$ group. Craniotomy was highly correlated with a favorable outcome $(p<0.001)$.

Intraoperative brain swelling was highly correlated both with high mortality $(p<0.001)$ and unfavorable outcome $(p<0.001)$.

The most common hematoma location was frontoparietal and frontotemporal regions $(n=61,56.5 \%)$ followed by the temporal $(n=29,26.9 \%)$, parietooccipital $(n=9,8.3 \%)$ and posterior fossa $(n=9,8.3 \%)$. As for hematoma location, our data showed data patients with hematoma in temporal location had statistically significant lower mortality rates $(p=<0.001)$.

Hematoma volume was closely related to mortality and functional outcome, i.e., the larger the hematoma volume the higher the incidence of mortality $(p<0.001)$ and unfavorable outcome $(p<0.001)$. Similarly, thickness of hematoma was also closely related to mortality and functional outcome, i.e., the thicker the hematoma the higher the incidence of mortality $(p<0.001)$ and unfavorable outcome $(p<0.001)$.

The degree of midline displacement measured on CT significantly correlated with both mortality and functional outcome. More displacement showed significantly higher mortality rates $(p<0.001)$ and higher unfavorable outcome $(p<0.001)$. However, the degree of the midline displacement was shown to have no affect in the mortality of the EDH patients $(p=0.135)$

Twenty-five patients (23.1\%) had associated SAH in CT scans, and all of these patients had an unfavorable outcome. Associated SAH was correlated with high mortality $(p=<0.001)$ and high unfavorable outcome $(p=<0.001)$ rates. Coincidental contusions were detected in $14.8 \%$ of patients and neither correlated with mortality $(p=0.699)$ nor with unfavorable outcome $(p=1.00)$. Coincidental lesions including $\mathrm{SAH}$ were neither correlated with mortality $(p=0.513)$ nor with the unfavorable outcome $(p=0.105)$ in the SDH subgroup.

The obliteration of the basal cisterns also significantly correlated with both high mortality $(p<0.001)$ and unfavorable outcome $(p<0.001)$. The patients in whom basal cisterns were obliterated showed $71.2 \%$ mortality and $93.9 \%$ unfavorable outcome; patients in whom basal cisterns were not obliterated showed $14.2 \%$ mortality and $23.8 \%$ unfavorable outcome.

Variables of mortality and functional outcome were analyzed in Table II and Table III respectively.

Results from the multivariable logistic regression analysis examining the association between mortality and significant 
Table II: Variables Related to Mortality among all Study Cohorts

\begin{tabular}{|c|c|c|c|}
\hline Variables & Survived $(n=55 ; 50.9 \%)$ & Death $(n=53 ; 49.1 \%)$ & p-value \\
\hline Diagnosis & & & $<0.001$ \\
\hline$S D H$ & $22(40 \%)$ & $41(77.4 \%)$ & \\
\hline$E D H$ & $33(60 \%)$ & $12(22.6 \%)$ & \\
\hline Age (year) & $37.3 \pm 17.3$ & $42.6 \pm 15.5$ & 0.1 \\
\hline Sex & & & 0.736 \\
\hline Male & $45(81.8 \%)$ & $42(79.2 \%)$ & \\
\hline Female & $10(18.2 \%)$ & $11(20.8 \%)$ & \\
\hline Admission GCS & $6(3-9)$ & $4(3-8)$ & $<0.001$ \\
\hline Pupil Reactivity & & & $<0.001$ \\
\hline Bilateral unresponsive & $1(1.8 \%)$ & $16(30.2 \%)$ & \\
\hline Unilateral unresponsive & $54(98.2 \%)$ & $37(69.8 \%)$ & \\
\hline Duration of ICU Stay (day) & $7(2-22)$ & $6(1-26)$ & 0.248 \\
\hline Postoperative ICP (mmHg) & $19(12-33)$ & $29(21-36)$ & $<0.001$ \\
\hline Herniation Type & & & $<0.001$ \\
\hline Bilateral uncal herniation & $1(1.8 \%)$ & $14(26.4 \%)$ & \\
\hline Ipsilateral uncal herniation & 52 (94.5\%) & $38(71.7 \%)$ & \\
\hline Kernohan's herniation & $2(3.6 \%)$ & $1(1.9 \%)$ & \\
\hline Time to Surgery & & & $<0.001$ \\
\hline$\leq 2$ hours & $30(54.5 \%)$ & $7(13.2 \%)$ & \\
\hline $2-4$ hours & $10(18.2 \%)$ & $14(26.4 \%)$ & \\
\hline$\geq 4$ hours & $15(27.3 \%)$ & $32(60.4 \%)$ & \\
\hline Operation Time (h) & $1.5(1-3)$ & $2(1-4)$ & $<0.001$ \\
\hline Herniation Duration (h) & $1(0.5-4)$ & $2(0.5-5)$ & $<0.001$ \\
\hline Surgery & & & $<0.001$ \\
\hline$C E$ & $17(30.9 \%)$ & $51(96.2 \%)$ & \\
\hline $\mathrm{CO}$ & $38(69.1 \%)$ & $2(3.8 \%)$ & \\
\hline Intraoperative Brain Swelling & & & $<0.001$ \\
\hline Available & $20(36.4 \%)$ & $51(96.2 \%)$ & \\
\hline None & 35 (63.6\%) & $2(3.8 \%)$ & \\
\hline Location & & & $<0.001$ \\
\hline Frontoparietal and frontotemporal & $24(43.6 \%)$ & $37(69.3 \%)$ & \\
\hline Temporal & $24(43.6 \%)$ & $5(9.4 \%)$ & \\
\hline Parietooccipital & $1(1.8 \%)$ & $8(15.1 \%)$ & \\
\hline Posterior fossa & $6(10.9 \%)$ & $3(5.7 \%)$ & \\
\hline Hematoma volume (mL) & $105(70-171)$ & $145(95-200)$ & $<0.001$ \\
\hline Hematoma thickness (mm) & $17(10-32)$ & $26(16-34)$ & $<0.001$ \\
\hline
\end{tabular}


Table II: Cont.

\begin{tabular}{|c|c|c|c|}
\hline Variables & Survived $(n=55 ; 50.9 \%)$ & Death $(n=53 ; 49.1 \%)$ & p-value \\
\hline Co-incidental lesion & & & $<0.001$ \\
\hline None & $42(76.4 \%)$ & $25(47.2 \%)$ & \\
\hline$S A H$ & $5(9.1 \%)$ & $20(37.7 \%)$ & \\
\hline Obliteration of Basal Cisterns & & & $<0.001$ \\
\hline Effaced & $19(34.5 \%)$ & $47(88.7 \%)$ & \\
\hline Not effaced & $36(65.5 \%)$ & $6(11.3 \%)$ & \\
\hline
\end{tabular}

EDH: Epidural hematoma, SDH: Subdural hematoma, GCS: Glasgow coma scale, ICU: Intensive care unit, ICP: Intracranial pressure, CE: Craniectomy, CO: Craniotomy, SAH: Subarachnoid hemorrhage.

Table III: Variables Related to Functional Outcome among all Study Cohorts

\begin{tabular}{|c|c|c|c|}
\hline Variables & $\begin{array}{l}\text { Unfavorable outcome }{ }^{1} \\
\qquad(\mathrm{n}=72,66.7 \%)\end{array}$ & $\begin{array}{c}\text { Favorable outcome }{ }^{2} \\
(n=36,33.3 \%)\end{array}$ & p-value \\
\hline Diagnosis & & & $<0.001$ \\
\hline$S D H$ & $57(79.2 \%)$ & $6(16.7 \%)$ & \\
\hline$E D H$ & $15(20.8 \%)$ & $30(83.3 \%)$ & \\
\hline Sex & & & 0.302 \\
\hline Male & $56(77.8 \%)$ & $31(86.1 \%)$ & \\
\hline Female & $16(22.2 \%)$ & $5(13.9 \%)$ & \\
\hline Admission GCS & $4(3-8)$ & $7(4-9)$ & $<0.001$ \\
\hline Duration of ICU Stay (day) & $7.5(1-26)$ & $7(2-22)$ & 0.837 \\
\hline Postoperative ICP (mmHg) & $29(16-36)$ & $15.5(12-28)$ & $<0.001$ \\
\hline Herniation Type & & & 0.018 \\
\hline Bilateral uncal herniation & $14(19.4 \%)$ & $1(2.8 \%)$ & \\
\hline Ipsilateral uncal herniation & $57(79.2 \%)$ & $33(91.7 \%)$ & \\
\hline Kernohan's herniation & $1(1.4 \%)$ & $2(5.6 \%)$ & \\
\hline Time to Surgery & & & $<0.001$ \\
\hline
\end{tabular}


Table III: Cont.

\begin{tabular}{|c|c|c|c|}
\hline Variables & $\begin{array}{l}\text { Unfavorable outcome }{ }^{1} \\
(n=72,66.7 \%)\end{array}$ & $\begin{array}{l}\text { Favorable outcome }{ }^{2} \\
(n=36,33.3 \%)\end{array}$ & p-value \\
\hline Surgery & & & $<0.001$ \\
\hline$C E$ & $65(90.3 \%)$ & $3(8.3 \%)$ & \\
\hline $\mathrm{CO}$ & $7(9.7 \%)$ & $33(91.7 \%)$ & \\
\hline Intraoperative Brain Swelling & & & $<0.001$ \\
\hline Available & $66(91.7 \%)$ & $5(13.9 \%)$ & \\
\hline None & $6(8.3 \%)$ & $31(86.1 \%)$ & \\
\hline Location & & & $<0.001$ \\
\hline Frontoparietal and frontotemporal & $49(68 \%)$ & $12(33.4 \%)$ & \\
\hline $\begin{array}{l}\text { Temporal } \\
\text { Parietooccipital }\end{array}$ & $\begin{array}{l}8(11.1 \%) \\
9(12.5 \%)\end{array}$ & $\begin{array}{c}21(58.3 \%) \\
-\end{array}$ & \\
\hline Posterior fossa & $6(8.3 \%)$ & $3(8.3 \%)$ & \\
\hline Hematoma volume $(\mathrm{mL})$ & $144(95-200)$ & $96(70-145)$ & $<0.001$ \\
\hline Hematoma thickness (mm) & $25(10-34)$ & $15(11-30)$ & $<0.001$ \\
\hline Midline Shift (mm) & $18(5-33)$ & $10(5-20)$ & $<0.001$ \\
\hline Co-incidental lesion & & & $<0.001$ \\
\hline None & $37(51.4 \%)$ & $30(83.3 \%)$ & \\
\hline$S A H$ & $25(34.7 \%)$ & - & \\
\hline Contusion & $10(13.9 \%)$ & $6(16.7 \%)$ & \\
\hline Obliteration of Basal Cisterns & & & $<0.001$ \\
\hline Effaced & $62(86.1 \%)$ & $4(11.1 \%)$ & \\
\hline Not effaced & $10(13.9 \%)$ & $32(88.9 \%)$ & \\
\hline
\end{tabular}

${ }^{1}$ Unfavorable outcome was determined as Glasgow Outcome Scale score 1, 2, and 3.

${ }^{2}$ Favorable outcome was determined as Glasgow Outcome Scale score 4, and 5.

EDH: Epidural hematoma, SDH: Subdural hematoma, GCS: Glasgow coma scale, ICU: Intensive care unit, ICP: Intracranial pressure, CE: Craniectomy, CO: Craniotomy, SAH: Subarachnoid hemorrhage.

predictors are shown in the Table IV. One of the most important predictors of mortality was the postoperative ICP value; where every $1 \mathrm{mmHg}$ raise in the postoperative ICP increased the mortality 1.64 times (95\% Cl: $1.246-2.172)$. Despite postoperative ICP, interval from the time of the trauma to the time of the hematoma decompression, thickness of the hematoma, the duration of the brain herniation and presence of $\mathrm{SAH}$ were determined to be the significant independent predictors of mortality.

The subgroup analyses of the EDH patients that are relevant to mortality and functional outcome are summarized in Table V and Table VI. Also, the subgroup analyses of the SDH patients that are relevant to mortality and functional outcome are summarized in Table VII and Table VIII.

\section{DISCUSSION}

The most important neurosurgical complication of head injury is the rapidly expanding intracranial hematoma causing brain herniation $(33,34)$. Despite early diagnosis and adequate surgery, mortality and morbidity of both EDH and SDH remain considerable. The majority of studies have reported a mortality rate of approximately $12 \%$ for acute traumatic EDH $(4,9,22,30)$ and $50-70 \%$ for acute SDH $(12,36,39,46,47)$. In this retrospective study of more than one decade of herniated head injured patients harboring an $\mathrm{EDH}$ or SHD, we reported our surgical results.

The results of our study demonstrated that overall mortality was $49.1 \%$ and only $34.4 \%$ of patients showed favorable outcome. Mortality rates for herniated SDH and EDH were $65.1 \%$ and $26.6 \%$ respectively. For $\mathrm{SDH}, 90.4 \%$ of the patients showed an unfavorable outcome; however only $33.3 \%$ of EDH 
Gurer B. et al: Traumatic Herniated Extraaxial Hematomas

Table IV: Multiple Logistic Regression Analysis Results for Variables Related to the Mortality

\begin{tabular}{|c|c|c|c|c|}
\hline \multirow{2}{*}{ Variables } & \multirow{2}{*}{ Odds Ratio } & \multicolumn{2}{|c|}{$95 \% \mathrm{Cl}$} & \multirow{2}{*}{ p-value } \\
\hline & & Lower Limit & Upper Limit & \\
\hline Time to Surgery & 0.655 & 0.435 & 0.987 & 0.043 \\
\hline Hematoma Thickness & 1.282 & 1.047 & 1.569 & 0.016 \\
\hline Herniation Duration & 3.529 & 1.315 & 9.474 & 0.012 \\
\hline
\end{tabular}

CI: Confidence interval, ICP: Intracranial pressure, SAH: Subarachnoid hemorrhage.

Table V: Variables Related to Mortality among Herniated Epidural Hematoma Patients

\begin{tabular}{|c|c|c|c|}
\hline Variables & Survived (n=33; 73.4\%) & Death $(n=12 ; 26.6 \%)$ & p-value \\
\hline Sex & & & 0.043 \\
\hline Male & 29 (87.9\%) & $7(58.3 \%)$ & \\
\hline Female & $4(12.1 \%)$ & $5(41.7 \%)$ & \\
\hline Pupil Reactivity & & & $<0.001$ \\
\hline Bilateral unresponsive & - & $7(58.3 \%)$ & \\
\hline Unilateral unresponsive & $33(100 \%)$ & $5(41.7 \%)$ & \\
\hline Duration of ICU Stay (day) & $6(2-22)$ & $12(2-26)$ & 0.025 \\
\hline Bilateral uncal herniation & - & $5(41.7 \%)$ & \\
\hline Ipsilateral uncal herniation & $32(97 \%)$ & $7(58.3 \%)$ & \\
\hline Kernohan's herniation & $1(3 \%)$ & - & \\
\hline Time to Surgery & & & 0.02 \\
\hline$\leq 2$ hours & $25(75.8 \%)$ & $4(33.3 \%)$ & \\
\hline 2-4 hours & $4(12.1 \%)$ & $2(16.7 \%)$ & \\
\hline$\geq 4$ hours & $4(12.1 \%)$ & $6(50 \%)$ & \\
\hline Operation Time (h) & $1.5(1-2)$ & $2(1-4)$ & 0.017 \\
\hline Intraoperative Brain Swelling & & & $<0.001$ \\
\hline Available & $6(18.2 \%)$ & $12(100 \%)$ & \\
\hline None & $27(81.8 \%)$ & - & \\
\hline Location & & & $<0.001$ \\
\hline
\end{tabular}


Table V: Cont.

\begin{tabular}{|c|c|c|c|}
\hline Variables & Survived ( $n=33 ; 73.4 \%)$ & Death $(n=12 ; 26.6 \%)$ & p-value \\
\hline Frontoparietal and frontotemporal & $10(30.3 \%)$ & $11(91.7 \%)$ & \\
\hline Temporal & 21 (63.6\%) & 1 (8.3\%) & \\
\hline Parietooccipital & $1(3 \%)$ & - & \\
\hline Posterior fossa & $1(3 \%)$ & - & \\
\hline Hematoma volume $(\mathrm{mL})$ & $96(75-154)$ & $166(100-200)$ & $<0.001$ \\
\hline Hematoma thickness (mm) & $16(11-32)$ & $25(16-33)$ & $<0.001$ \\
\hline Midline Shift (mm) & $10(5-22)$ & $16(5-21)$ & 0.135 \\
\hline Co-incidental lesion & & & $<0.001$ \\
\hline None & $28(84.8 \%)$ & $3(25 \%)$ & \\
\hline$S A H$ & $5(9.1 \%)$ & $20(37.7 \%)$ & \\
\hline Contusion & $1(3 \%)$ & $7(58.3 \%)$ & \\
\hline Obliteration of Basal Cisterns & & & $<0.001$ \\
\hline Effaced & $4(12.1 \%)$ & $12(100 \%)$ & \\
\hline Not effaced & $29(87.9 \%)$ & - & \\
\hline
\end{tabular}

EDH: Epidural hematoma, SDH: Subdural hematoma, GCS: Glasgow coma scale, ICU: Intensive care unit, ICP: Intracranial pressure, CE: Craniectomy, CO: Craniotomy, SAH: Subarachnoid hemorrhage.

showed an unfavorable outcome. Our study demonstrated that herniated SDH patients showed the highest mortality and the most unfavorable outcome.

Several authors reported that older age is associated with a higher mortality for TBI $(10,14,18,19,27,29,46)$. Our age data conflicts with prior studies. Thus, in our study of the herniated subgroup of traumatic extraaxial hematomas, age does not appear to be associated either with mortality or an unfavorable outcome.

We found the motor vehicle accidents as the leading cause of trauma followed by falls, pedestrian injuries, assaults, motorcycle accidents, and bicycle accidents; the mechanism of the trauma showed no significant effect on mortality or functional outcome rates.

Initial GCS scores have been reported to be a good predictor of outcome for patients both with $\operatorname{EDH}(4,5,15,20,22,23,43,45)$ and with $\operatorname{SDH}(6,7,29,33,42)$. In our study, almost all patients with herniated extraaxial hematoma were comatose and had GCS scores equal to or lower than 9. Like other studies, we also found that mortality and unfavorable outcome were highly correlated with low GCS scores.

Pupils that are bilaterally unresponsive to light are associated with a high mortality $(4,8,9,25,30,45)$. Patients with bilateral fixed and dilated pupils at surgery had $0-13 \%$ favorable outcome and $64-93 \%$ mortality rate $(13,29,31,38,46)$. In our series, mortality was $94.1 \%$ for patients with bilateral unresponsive pupils; and only one of these patients $(6.9 \%)$ had a favorable outcome. Statistically, we showed that having bilateral unresponsive pupils was significantly correlated with high mortality and unfavorable outcome. In the SDH subgroup, bilateral unresponsive pupils were not correlated with high mortality and unfavorable outcome.

Monitoring of ICP is an important treatment option for patients with severe TBI. ICP monitoring is recommended by all available guidelines for management of severe TBI $(1,3)$. There are a few studies available in which postoperative ICP and its relation to outcome was structured (23). In this study, all our patients were monitored with a continuous postoperative ICP monitor. Mean postoperative ICP values for patients who died was $29 \mathrm{mmHg}$ (range 21-36 mmHg) while it was $19 \mathrm{mmHg}$ (range 12-33 $\mathrm{mmHg}$ ) for patients who survived. We therefore concluded that mortality was highly correlated with high mean postoperative ICP values. Similarly, patients with favorable outcome showed lower postoperative ICP values (mean $15.5 \mathrm{mmHg}$; range $12-28 \mathrm{mmHg}$ ) compared to patients with unfavorable outcome (mean $29 \mathrm{mmHg}$; range 16-36 $\mathrm{mmHg}$ ). As a result of multivariable logistic regression analysis, our study demonstrated that one of the most important predictors of mortality was the postoperative ICP values. Every $1 \mathrm{mmHg}$ raise in the postoperative ICP increased the probability of mortality 1.64 times.

Brain herniation is most commonly recognized clinically by deterioration in consciousness with unilateral or bilateral papillary dilatation (37), and hemiparesis (22). The type of the brain herniation was also associated with mortality. Bilateral herniation was reported to cause $64-88 \%$ mortality $(29,31,35,41)$. Similarly, in our study, bilateral uncal herniation caused $93.3 \%$ mortality whereas mortality of unilateral uncal herniation was $42.2 \%$. Furthermore, the type of brain herniation was not associated with mortality and functional outcome rates in the SDH subgroup. 
Gurer B. et al: Traumatic Herniated Extraaxial Hematomas

Table VI: Variables Related to Functional Outcome among Herniated Epidural Hematoma Patients

\begin{tabular}{|c|c|c|c|}
\hline Variables & $\begin{array}{c}\text { Unfavorable outcome }{ }^{1} \\
(n=15,33.3 \%)\end{array}$ & $\begin{array}{l}\text { Favorable outcome }{ }^{2} \\
\quad(n=30,66.7 \%)\end{array}$ & p-value \\
\hline Age (year) & $38.1 \pm 13.9$ & $35.9 \pm 16.3$ & 0.658 \\
\hline Sex & & & 0.135 \\
\hline Male & $10(66.7 \%)$ & $26(86.7 \%)$ & \\
\hline Female & $5(33.3 \%)$ & $4(13.3 \%)$ & \\
\hline Admission GCS & $4(3-8)$ & $7(4-9)$ & $<0.001$ \\
\hline Pupil Reactivity & & & $<0.001$ \\
\hline Bilateral unresponsive & $7(46.7 \%)$ & - & \\
\hline Unilateral unresponsive & $8(53.3 \%)$ & $30(100 \%)$ & \\
\hline Duration of ICU Stay (day) & $12(2-26)$ & $6(2-22)$ & 0.038 \\
\hline Postoperative ICP (mmHg) & $29(19-35)$ & $15(12-28)$ & $<0.001$ \\
\hline Herniation Type & & & 0.02 \\
\hline Bilateral uncal herniation & $5(33.3 \%)$ & - & \\
\hline Ipsilateral uncal herniation & $10(66.7 \%)$ & $29(96.7 \%)$ & \\
\hline Kernohan's herniation & - & $1(3.3 \%)$ & \\
\hline Time to Surgery & & & 0.006 \\
\hline$\leq 2$ hours & $5(33.3 \%)$ & $24(80 \%)$ & \\
\hline $2-4$ hours & $3(20 \%)$ & $3(10 \%)$ & \\
\hline$\geq 4$ hours & $7(46.7 \%)$ & $3(10 \%)$ & \\
\hline Operation Time (h) & $2(1-4)$ & $1.2(1-2)$ & $<0.001$ \\
\hline Herniation Duration (h) & $1.5(1-4)$ & $0.5(0.5-2)$ & $<0.001$ \\
\hline Surgery & & & $<0.001$ \\
\hline$C E$ & $13(86.7 \%)$ & $2(6.7 \%)$ & \\
\hline $\mathrm{CO}$ & $2(13.3 \%)$ & $28(93.3 \%)$ & \\
\hline Intraoperative Brain Swelling & & & $<0.001$ \\
\hline Available & $14(93.3 \%)$ & $4(13.3 \%)$ & \\
\hline None & $1(6.7 \%)$ & $26(86.7 \%)$ & \\
\hline Location & & & $<0.001$ \\
\hline Frontoparietal and frontotemporal & $12(80 \%)$ & $9(30 \%)$ & \\
\hline Temporal & $2(13.3 \%)$ & $20(66.7 \%)$ & \\
\hline Parietooccipital & $1(6.7 \%)$ & - & \\
\hline Posterior fossa & - & $1(3.3 \%)$ & \\
\hline Hematoma volume (mL) & $154(100-200)$ & $96(75-145)$ & $<0.001$ \\
\hline Hematoma thickness (mm) & $25(16-33)$ & $15(11-30)$ & $<0.001$ \\
\hline Midline Shift (mm) & $16(5-22)$ & $10(5-20)$ & 0.023 \\
\hline Co-incidental lesion & & & $<0.001$ \\
\hline None & $5(33.3 \%)$ & $26(86.7 \%)$ & \\
\hline
\end{tabular}


Table Vl: Cont.

\begin{tabular}{|c|c|c|c|}
\hline Variables & $\begin{array}{c}\text { Unfavorable outcome }{ }^{1} \\
(n=15,33.3 \%)\end{array}$ & $\begin{array}{l}\text { Favorable outcome }{ }^{2} \\
\quad(n=30,66.7 \%)\end{array}$ & p-value \\
\hline$S A H$ & 8 (53.3\%) & - & \\
\hline Contusion & $2(13.3 \%)$ & 4 (13.3\%) & \\
\hline Obliteration of Basal Cisterns & & & $<0.001$ \\
\hline Effaced & $14(93.3 \%)$ & $2(6.7 \%)$ & \\
\hline Not effaced & $1(6.7 \%)$ & $28(93.3 \%)$ & \\
\hline
\end{tabular}

${ }^{1}$ Unfavorable outcome was determined as Glasgow Outcome Scale score 1, 2, and 3.

${ }^{2}$ Favorable outcome was determined as Glasgow Outcome Scale score 4, and 5.

EDH: Epidural hematoma, SDH: Subdural hematoma, GCS: Glasgow coma scale, ICU: Intensive care unit, ICP: Intracranial pressure, CE: Craniectomy, CO: Craniotomy, SAH: Subarachnoid hemorrhage.

The Brain Trauma Foundation and the Congress of Neurological Surgeons have recommended that surgical evacuation must be performed "as soon as possible" in patients with herniation syndromes (5). Time from trauma until surgical decompression affects the mortality. Many authors have observed that the sooner surgery is performed in cases of acute head trauma, the better the final results are $(6,12,14,16,21,41,46)$. Seelig et al. (32) reported considerable decline in the rates of mortality and morbidity of the patients operated in the first four hours after the trauma compared to those operated upon later. Our data also showed that a longer interval from the time of the trauma to the time of the hematoma decompression was significantly correlated with high mortality and high unfavorable outcome rates.

In the case of brain herniation, immediate surgery can be life saving. With delay to decompression, patients who suffered from brain herniation syndromes have increased rates of permanent disability and death (5). Some authors also reported that the critical time is not the time from injury, but the time from the onset of symptomatic brain compression $(8,12,22,26)$. Haselsberger et al. (12) reported that mortality rose from $17 \%$ to $65 \%$ and good recovery dropped from $67 \%$ to $13 \%$ when the time from the onset of coma to operation was more than 2 hours. In a prospective study, Lee et al. (22), showed that favorable outcomes dropped progressively through herniation time. We also demonstrated that the longer the period of brain herniation, the higher the incidences of both mortality and unfavorable outcome. In other words, our study demonstrated that in patients with both herniated SDH and $\mathrm{EDH}$, the prognosis is affected by the timing of the operation and the duration of the brain herniation. Those operated soon after the trauma and soon after the onset of brain herniation have lower mortality and increased rate of favorable outcome.

Mortality and unfavorable outcome in our study was higher in the patients for whom CE was performed than the patients for whom CO was performed but this difference was likely to be caused by the high proportion of patients with the signs of the acute brain swelling and bilateral brain herniation in the CE group.

Intraoperative acute brain swelling seems to be a strong predictor of poor outcome for the patients with TBI $(18,24,41)$.
Similarly, our data showed that intraoperative brain swelling was highly correlated both with mortality and unfavorable outcome.

CT is the imaging study of choice for the diagnosis of an extraaxial hematoma. CT also allows the identification of additional features that affect outcome such as hematoma volume, thickness of the hematoma, midline shift, SAH and obliteration of the basal cisterns (5). In a series of 200 patients who were treated surgically for EDH, Lee et al. (22), found that a hematoma volume greater than $50 \mathrm{~cm}^{3}$ was significantly related to high mortality and unfavorable functional outcome. Yanaka et al. (48), showed that greater hematoma volume and the thickness of SDH was associated with poor outcome and mortality. Many other authors reported similar findings for both $\mathrm{EDH}$ and SDH $(11,22,30,45)$. We also demonstrated in our study that the larger the hematoma volume and the thickness, the higher the incidence of mortality and unfavorable outcome.

The presence and the degree of the midline shift were reported to be associated with worse recovery and high mortality $(2,10,25,44)$. Our data also concluded that more displacement of the midline structures was associated with high mortality and unfavorable functional outcome.

The association of traumatic SAH with extraaxial hematoma was determined in $23.1 \%$ of the study patients, and all of these patients had an unfavorable outcome. Detection of traumatic SAH in the initial CT was strongly correlated with high mortality and unfavorable outcome. We also found that obliteration of the basal cisterns was significantly correlated both with high mortality and unfavorable outcome.

According to our data, the most important predictors of mortality were the interval from time of the trauma to the time of hematoma decompression, postoperative ICP, thickness of the hematoma, the duration of the brain herniation and the presence of $\mathrm{SAH}$.

\section{CONCLUSION}

Brain herniation due to traumatic $\mathrm{EDH}$ and SDH causes catastrophic consequences. High mortality and unfavorable outcome rates are associated with GCS scores at admission, 
mean postoperative ICP values, type of the brain herniation, interval from the time of trauma to the time of hematoma decompression, the duration of the brain herniation, intraoperative acute brain swelling, hematoma volume and thickness, degree of the midline shift and the obliteration of the basal cisterns.
Postoperative ICP values are the most important predictors of the mortality. We recommend postoperative ICP monitoring for all patients presenting with brain herniation due to traumatic extraaxial hematoma.

Table VII: Variables Related to Mortality among Herniated Subdural Hematoma Patients

\begin{tabular}{|c|c|c|c|}
\hline Variables & Survived $(n=22 ; 34.9 \%)$ & Death (n=41; 65.1\%) & p-value \\
\hline Age (year) & $41.1 \pm 19$ & $42.9 \pm 16.2$ & 0.684 \\
\hline Sex & & & 0.314 \\
\hline Male & $16(72.7 \%)$ & $35(85.4 \%)$ & \\
\hline Female & $6(27.3 \%)$ & $6(14.6 \%)$ & \\
\hline Admission GCS & $6(3-8)$ & $4(3-8)$ & $<0.001$ \\
\hline Pupil Reactivity & & & 0.145 \\
\hline Bilateral unresponsive & $1(4.5 \%)$ & $9(22 \%)$ & \\
\hline Unilateral unresponsive & $21(95.5 \%)$ & $32(78 \%)$ & \\
\hline Duration of ICU Stay (day) & $11(2-22)$ & $5(1-25)$ & 0.002 \\
\hline Postoperative ICP (mmHg) & $23(14-32)$ & $29(21-36)$ & $<0.001$ \\
\hline Herniation Type & & & 0.14 \\
\hline Bilateral uncal herniation & $1(4.5 \%)$ & $9(22 \%)$ & \\
\hline Ipsilateral uncal herniation & 20 (90.9\%) & $31(75.6 \%)$ & \\
\hline Kernohan's herniation & $1(4.5 \%)$ & $1(2.4 \%)$ & \\
\hline Time to Surgery & & & 0.008 \\
\hline$\leq 2$ hours & $5(22.7 \%)$ & $3(7.3 \%)$ & \\
\hline 2-4 hours & $6(27.3 \%)$ & $12(29.3 \%)$ & \\
\hline$\geq 4$ hours & $11(50 \%)$ & $26(63.4 \%)$ & \\
\hline Operation Time (h) & $2(1-3)$ & $2(1-4)$ & 0.485 \\
\hline Herniation Duration (h) & $1(0.5-4)$ & $2(0.5-5)$ & 0.002 \\
\hline Surgery & & & 0.002 \\
\hline$C E$ & $14(63.6 \%)$ & $39(95.1 \%)$ & \\
\hline $\mathrm{CO}$ & $8(36.4 \%)$ & $2(4.9 \%)$ & \\
\hline Intraoperative Brain Swelling & & & 0.002 \\
\hline Available & $14(63.6 \%)$ & 39 (95.1\%) & \\
\hline None & $8(36.4 \%)$ & $2(4.9 \%)$ & \\
\hline Location & & & 0.047 \\
\hline Frontoparietal and frontotemporal & $14(63.7 \%)$ & $26(63.4 \%)$ & \\
\hline $\begin{array}{l}\text { Temporal } \\
\text { Parietooccipital }\end{array}$ & $\begin{array}{c}3(13.6 \%) \\
-\end{array}$ & $\begin{array}{l}4(9.8 \%) \\
8(19.5 \%)\end{array}$ & \\
\hline Posterior fossa & 5 (22.7\%) & $3(7.3 \%)$ & \\
\hline Hematoma volume $(\mathrm{mL})$ & $114.5(70-171)$ & $143(95-190)$ & 0.005 \\
\hline
\end{tabular}


Table VII: Cont.

\section{Variables}

Hematoma thickness (mm)

Midline Shift (mm)

Co-incidental lesion

None

$S A H$

Contusion

Obliteration of Basal Cisterns

Effaced

Not effaced
Survived ( $\mathrm{n}=22 ; 34.9 \%)$

21 (10-29)

$13(5-28)$

$14(63.6 \%)$

$4(18.2 \%)$

$4(18.2 \%)$

$15(68.2 \%)$

7 (31.8\%)

\begin{tabular}{cc} 
Death $(\mathbf{n}=\mathbf{4 1 ;} \mathbf{6 5 . 1 \% )}$ & p-value \\
\hline $26(20-34)$ & $<0.001$ \\
$19(10-33)$ & $<0.001$ \\
& 0.513 \\
\hline $22(53.7 \%)$ & \\
$13(31.7 \%)$ & \\
$6(14.6 \%)$ & 0.190 \\
\hline $35(85.4 \%)$ & \\
$6(14.6 \%)$ & \\
\hline
\end{tabular}

EDH: Epidural hematoma, SDH: Subdural hematoma, GCS: Glasgow coma scale, ICU: Intensive care unit, ICP: Intracranial pressure, CE: Craniectomy, CO: Craniotomy, SAH: Subarachnoid hemorrhage.

Table VIII: Variables Related to Functional Outcome among Herniated Subdural Hematoma Patients

\begin{tabular}{|c|c|c|c|}
\hline Variables & $\begin{array}{c}\text { Unfavorable outcome }{ }^{1} \\
(n=57,90.4 \%)\end{array}$ & $\begin{array}{c}\text { Favorable outcome } \\
(n=6,9.6 \%)\end{array}$ & p-value \\
\hline Age (year) & $41 \pm 16.6$ & $54.8 \pm 17.6$ & 0.058 \\
\hline Sex & & & 1 \\
\hline Male & $46(80.7 \%)$ & $5(83.3 \%)$ & \\
\hline Female & $11(19.3 \%)$ & $1(16.7 \%)$ & \\
\hline Admission GCS & $4(3-8)$ & $7.5(4-8)$ & 0.003 \\
\hline Pupil Reactivity & & & 1 \\
\hline Bilateral unresponsive & $9(15.8 \%)$ & $1(16.7 \%)$ & \\
\hline Unilateral unresponsive & $48(84.2 \%)$ & $5(83.3 \%)$ & \\
\hline Duration of ICU Stay (day) & $6(1-25)$ & $12.5(10-22)$ & 0.015 \\
\hline Postoperative ICP (mmHg) & $28(16-36)$ & $19.5(14-25)$ & $<0.001$ \\
\hline Herniation Type & & & 0.315 \\
\hline Bilateral uncal herniation & $9(15.8 \%)$ & $1(216.7 \%)$ & \\
\hline Ipsilateral uncal herniation & $47(82.5 \%)$ & $4(66.7 \%)$ & \\
\hline Kernohan's herniation & $1(1.8 \%)$ & $1(16.7 \%)$ & \\
\hline Time to Surgery & & & 0.002 \\
\hline$\leq 2$ hours & $5(8.8 \%)$ & $3(50 \%)$ & \\
\hline 2-4 hours & $15(26.3 \%)$ & $3(50 \%)$ & \\
\hline$\geq 4$ hours & $37(64.9 \%)$ & - & \\
\hline Operation Time (h) & $2(1-4)$ & $2(1-2.5)$ & 0.882 \\
\hline Herniation Duration (h) & $2(0.5-5)$ & $1(0.5-1)$ & 0.009 \\
\hline
\end{tabular}


Table VIII: Cont.

\begin{tabular}{|c|c|c|c|}
\hline Variables & $\begin{array}{l}\text { Unfavorable outcome }{ }^{1} \\
\qquad(n=57,90.4 \%)\end{array}$ & $\begin{array}{l}\text { Favorable outcome }{ }^{2} \\
\qquad(n=6,9.6 \%)\end{array}$ & p-value \\
\hline Surgery & & & $<0.001$ \\
\hline$C E$ & $52(91.2 \%)$ & $1(16.7 \%)$ & \\
\hline $\mathrm{CO}$ & $5(8.8 \%)$ & $5(83.3 \%)$ & \\
\hline Available & $52(91.2 \%)$ & $1(16.7 \%)$ & \\
\hline None & $5(8.8 \%)$ & $5(83.3 \%)$ & \\
\hline Location & & & 0.44 \\
\hline Frontoparietal and frontotemporal & 37 (64.9\%) & $3(50 \%)$ & \\
\hline Hematoma volume (mL) & $143(95-190)$ & $100(70-115)$ & $<0.001$ \\
\hline Hematoma thickness (mm) & $25(10-34)$ & $14.5(13-29)$ & 0.005 \\
\hline Midline Shift (mm) & $18(5-33)$ & $11(7-14)$ & $<0.001$ \\
\hline Co-incidental lesion & & & 0.105 \\
\hline None & $32(56.1 \%)$ & $4(66.7 \%)$ & \\
\hline$S A H$ & $17(29.8 \%)$ & - & \\
\hline Contusion & $8(14 \%)$ & $2(33.3 \%)$ & \\
\hline
\end{tabular}

${ }^{1}$ Unfavorable outcome was determined as Glasgow Outcome Scale score 1 and 2.

${ }^{2}$ Favorable outcome was determined as Glasgow Outcome Scale score 3, 4, and 5.

EDH: Epidural hematoma, SDH: Subdural hematoma, GCS: Glasgow coma scale, ICU: Intensive care unit, ICP: Intracranial pressure, CE: Craniectomy, CO: Craniotomy, SAH: Subarachnoid hemorrhage.

\section{REFERENCES}

1. American Association for the Surgery of Trauma; Child Neurology Society; International Society for Pediatric Neurosurgery; International Trauma Anesthesia and Critical Care Society; Society of Critical Care Medicine; World Federation of Pediatric Intensive and Critical Care Societies; National Center for Medical Rehabilitation Research; National Institute of Child Health and Human Development; National Institute of Neurological Disorders and Stroke; Synthes USA; International Brain Injury Association: Guidelines for the acute medical management of severe traumatic brain injury in infants, children, and adolescents. J Trauma 54: S235-310, 2003

2. Becker DP, Miller JD, Ward JD, Greenberg RP, Young HF, Sakalas R: The outcome from severe head injury with early diagnosis and intensive management. J Neurosurg 47:491502,1977
3. Brain Trauma Foundation; American Association of Neurological Surgeons; Congress of Neurological Surgeons; Joint Section on Neurotrauma and Critical Care, AANS/CNS, Bratton SL, Chestnut RM, Ghajar J, McConnell Hammond FF, Harris OA, Hartl R, Manley GT, Nemecek A, Newell DW, Rosenthal G, Schouten J, Shutter L, Timmons SD, Ullman JS, Videtta W, Wilberger JE, Wright DW: Guidelines for the management of severe traumatic brain injury. VI. Indications for intracranial pressure monitoring. J Neurotrauma 24: S37-44, 2007

4. Bricolo AP, Pasut LM: Extradural hematoma: Toward zero mortality. A prospective study. Neurosurgery 14: 8-12, 1984

5. Bullock MR, Chesnut R, Ghajar J, Gordon D, Hartl R, Newell DW, Servadei F, Walters BC, Wilberger JE: Surgical management of acute epidural hematomas. Neurosurgery 58 : S7-15, 2006 
6. Bullock MR, Chesnut R, Ghajar J, Gordon D, Hartl R, Newell DW, Servadei F, Walters BC, Wilberger JE: Surgical management of acute subdural hematomas. Neurosurgery 58: S16-24, 2006

7. Chen SH, Chen Y, Fang WK, Huang DW, Huang KC, Tseng SH: Comparison of craniotomy and decompressive craniectomy in severely head-injured patients with acute subdural hematoma. J Trauma 71: 1632-1636, 2011

8. Cohen JE, Montero A, Israel ZH: Prognosis and clinical relevance of anisocoria-craniotomy latency for epidural hematoma in comatose patients. J Trauma 41: 120-122, 1996

9. Cordobés F, Lobato RD, Rivas JJ, Muñoz MJ, Chillón D, Portillo JM, Lamas E: Observations on 82 patients with extradural hematoma. Comparison of results before and after the advent of computerized tomography. J Neurosurg 54: 179-186, 1981

10. D’Amato L, Piazza O, Alliata L, Sabia G, Zito G, Frassanito L, Della Corte F, Tufano R: Prognosis of isolated acute posttraumatic subdural haematoma. J Neurosurg Sci 51:107-111, 2007

11. Eisenberg HM, Gary HE Jr, Aldrich EF, Saydjari C, Turner B, Foulkes MA, Jane JA, Marmarou A, Marshall LF, Young HF: Initial CT findings in 753 patients with severe head injury. A report from the NIH Traumatic Coma Data Bank. J Neurosurg 73: 688-698, 1990

12. Haselsberger K, Pucher R, Auer LM: Prognosis after acute subdural or epidural haemorrhage. Acta Neurochir (Wien) 90: 111-116, 1988

13. Hatashita S, Koga N, Hosaka Y, Takagi S: Acute subdural hematoma: Severity of injury, surgical intervention, and mortality. Neurol Med Chir (Tokyo) 33:13-18, 1993

14. Howard MA 3rd, Gross AS, Dacey RG Jr, Winn HR: Acute subdural hematomas: An age-dependent clinical entity. J Neurosurg 71: 858-863, 1989

15. Jennett $B$, Bond $M$ : Assessment of outcome after severe brain damage. Lancet 1:480-484, 1975

16. Karasu A, Civelek E, Aras Y, Sabanci PA, Cansever T, Yanar H, Sağlam G, Imer M, Hepgül KT, Taviloğlu K, Canbolat A: Analyses of clinical prognostic factors in operated traumatic acute subdural hematomas. Ulus Travma Acil Cerrahi Derg 16: 233-236, 2010

17. Kernohan JW, Woltman HW: Incisura of the crus due to contralateral brain tumor. Arch Neurol Psychiatry 21: 274-287, 1929

18. Kim KH: Predictors for functional recovery and mortality of surgically treated traumatic acute subdural hematomas in 256 patients. J Korean Neurosurg Soc 45:143-150, 2009

19. Kotwica Z, Brzeziński J: Acute subdural haematoma in adults: An analysis of outcome in comatose patients. Acta Neurochir (Wien) 121: 95-99, 1993

20. Kuday C, Uzan M, Hanci M: Statistical analysis of the factors affecting the outcome of extradural haematomas: 115 cases. Acta Neurochir (Wien) 131: 203-206, 1994

21. Leach P, Childs C, Evans J, Johnston N, Protheroe R, King A: Transfer times for patients with extradural and subdural haematomas to neurosurgery in Greater Manchester. $\mathrm{Br} \mathrm{J}$ Neurosurg 21: 11-15, 2007
22. Lee EJ, Hung YC, Wang LC, Chung KC, Chen HH: Factors influencing the functional outcome of patients with acute epidural hematomas: Analysis of 200 patients undergoing surgery. J Trauma 45: 946-952, 1998

23. Lobato RD, Rivas JJ, Cordobes F, Alted E, Perez C, Sarabia R, Cabrera A, Diez I, Gomez P, Lamas E: Acute epidural hematoma: An analysis of factors influencing the outcome of patients undergoing surgery in coma. J Neurosurg 68: 48-57, 1988

24. Marmarou A, Fatouros PP, Barzó P, Portella G, Yoshihara M, Tsuji O, Yamamoto T, Laine F, Signoretti S, Ward JD, Bullock MR, Young HF: Contribution of edema and cerebral blood volume to traumatic brain swelling in head-injured patients. $J$ Neurosurg 93: 183-193, 2000

25. Marshall LF, Toole BM, Bowers SA: The national traumatic coma data bank. Part 2: Patients who talk and deteriorate: Implications for treatment. J Neurosurg 59: 285-288, 1983

26. Nelson JA: Local skull trephination before transfer is associated with favorable outcomes in cerebral herniation from epidural hematoma. Acad Emerg Med 18: 78-85, 2011

27. Ono J, Yamaura A, Kubota M, Okimura Y, Isobe K: Outcome prediction in severe head injury: Analyses of clinical prognostic factors. J Clin Neurosci 8: 120-123, 2001

28. Petersen OF, Espersen JO: Extradural hematomas: Measurement of size by volume summation on CT scanning. Neuroradiology 26: 363-367, 1984

29. Phuenpathom N, Choomuang M, Ratanalert S: Outcome and outcome prediction in acute subdural hematoma. Surg Neurol 40: 22-25, 1993

30. Rivas JJ, Lobato RD, Sarabia R, Cordobés F, Cabrera A, Gomez $P$ : Extradural hematoma: Analysis of factors influencing the courses of 161 patients. Neurosurgery 23: 44-51, 1988

31. Sakas DE, Bullock MR, Teasdale GM: One-year outcome following craniotomy for traumatic hematoma in patients with fixed dilated pupils. J Neurosurg 82: 961-965, 1995

32. Seelig JM, Becker DP, Miller JD, Greenberg RP, Ward JD, Choi SC: Traumatic acute subdural hematoma: Major mortality reduction in comatose patients treated within four hours. $\mathrm{N}$ Engl J Med 304: 1511-1518, 1981

33. Servadei F: Prognostic factors in severely head injured adult patients with acute subdural haematomas. Acta Neurochir (Wien) 139: 279-285, 1997

34. Servadei F: Prognostic factors in severely head injured adult patients with epidural haematomas. Acta Neurochir (Wien) 139: 273-278, 1997

35. Servadei F, Nasi MT, Giuliani G, Cremonini AM, Cenni P, Zappi D, Taylor GS: CT prognostic factors in acute subdural haematomas: The value of the 'worst' CT scan. Br J Neurosurg 14: 110-116, 2000

36. Shenkin HA: Acute subdural hematoma. Review of 39 consecutive cases with high incidence of cortical artery rupture. J Neurosurg 57: 254-257, 1982

37. Skoglund TS, Nellgård B: Long-time outcome after transient transtentorial herniation in patients with traumatic brain injury. Acta Anaesthesiol Scand 49: 337-340, 2005 
38. Stening WA, Berry G, Dan NG, Kwok B, Mandryk JA, Ring I, Sewell M, Simpson DA: Experience with acute subdural haematomas in New South Wales. Aust N Z J Surg 56:549556, 1986

39. Stone JL, Lowe RJ, Jonasson O, Baker RJ, Barrett J, Oldershaw JB, Crowell RM, Stein RJ: Acute subdural hematoma: Direct admission to a trauma center yields improved results. J Trauma 26: 445-450, 1986

40. Thurman D, Guerrero J: Trends in hospitalization associated with traumatic brain injury. JAMA 282: 954-957, 1999

41. Tian HL, Chen SW, Xu T, Hu J, Rong BY, Wang G, Gao WW, Chen $\mathrm{H}$ : Risk factors related to hospital mortality in patients with isolated traumatic acute subdural haematoma: Analysis of 308 patients undergone surgery. Chin Med J (Engl) 121: 1080-1084, 2008

42. Tien HC, Jung V, Pinto R, Mainprize T, Scales DC, Rizoli SB: Reducing time-to-treatment decreases mortality of trauma patients with acute subdural hematoma. Ann Surg 253: 11781183,2011
43. Uzan M, Yentür E, Hanci M, Kaynar MY, Kafadar A, Sarioglu AC, Bahar M, Kuday C: Is it possible to recover from uncal herniation? Analysis of 71 head injured cases. J Neurosurg Sci 42: 89-94, 1998

44. Valadka AB, Gopinath SP, Robertson CS: Midline shift after severe head injury: Pathophysiologic implications. J Trauma 49: 1-8, 2000

45. van den Brink WA, Zwienenberg M, Zandee SM, van der Meer L, Maas Al, Avezaat CJ: The prognostic importance of the volume of traumatic epidural and subdural haematomas revisited. Acta Neurochir (Wien) 141: 509-514, 1999

46. Wilberger JE Jr, Harris M, Diamond DL: Acute subdural hematoma: Morbidity, mortality, and operative timing. J Neurosurg 74: 212-218, 1991

47. Wu JJ, Hsu CC, Liao SY, Wong YK: Surgical outcome of traumatic intracranial hematoma at a regional hospital in Taiwan. J Trauma 47: 39-43, 1999

48. Yanaka K, Kamezaki T, Yamada T, Takano S, Meguro K, Nose T: Acute subdural hematoma-prediction of outcome with a linear discriminant function. Neurol Med Chir (Tokyo) 33:552558,1993 